\title{
REVOLUCIÓN Y CONTRARREVOLUCIÓN: MILITARES Y REPUBLICANOS ENLA CIUDAD DE CÁDIZ DURANTE LA GUERRA CIVIL ESPAÑOLA, 1936-1939
}

\author{
JOAQUÍN PIÑEIRO BLANCA \\ Universidad de Cádiz
}

El ejército de África se sublevó contra la República el 17 de julio de 1936. Al día siguiente, tropas destacadas en las cercanas ciudades de Cádiz y Sevilla se sumarían a los insurrectos bajo el mando de Varela, López Pintos y Queipo de Llano. Otras ciudades andaluzas seguirían el ejemplo en las provincias de Córdoba y Huelva, en esta última tras ser sometidos los mineros de Riotinto.

Por ello, en los primeros días del llamado «Alzamiento» habían quedado delimitadas con claridad las dos zonas de influencia. La militarada se había impuesto en Andalucía occidental y en la ciudad de Granada (coronel Muñoz), mientras que la República había logrado resistir en la zona oriental, concretamente en Málaga, Almería, Jaén y la provincia de Granada (1).

\section{El estallido de la guerra: las tropas nacionales toman la ciudad}

Los sucesos del 18 de julio en Cádiz tuvieron lugar de forma muy acelerada. El gobernador civil, Mariano Zapico, celebró reuniones en las que se intentaba tomar medidas para impedir que el movimiento militar triunfase -una de estas decisiones fue la detención del general Varela, aunque sólo por unas horas-. A éstas se sumó el Ayuntamiento.

A las cinco y media de la tarde tropas de Infantería y Artillería se dirigieron hacia el Gobierno Civil, la primera por la Cuesta de las Calesas, al mando del general Varela, y la segunda desde la Alameda de Apodaca. Un grupo de obreros, desde azoteas de casas del barrio de Santa María y en el torreón de Puertas de Tierra, abrieron fuego a su paso pero sin resultados ya que pronto fueron reducidos.

Durante la tarde, las guamiciones rodearon los edificios del Gobierno Civil, el Ayuntamiento y Correos. Como Zapico no aceptó la rendición, el Palacio Provincial fue ametrallado continuadamente hasta el amanecer. Por la noche, las iglesias de Santo Domingo, el Carmen, San José y Santiago, los colegios de La Viña y Mirandilla y el Centro Católico Obrero fueron asaltados. Mientras, en el Casino Gaditano se concentraron los que se unieron a la sublevación de las tropas nacionales.

$\mathrm{Al}$ amanecer del día 19, el «Churruca» desembarcó en Cádiz efectivos procedentes de Marruecos, lo que terminó provocando la rendición de los representantes del Gobiemo (2). Asimismo, se abrió un puente aéreo entre 
Marruecos y Sevilla a fin de permitir la llegada de fuerzas aereotransportadas al velódromo de Tablada. El golpe militar del 18 de julio contra la República había triunfado en Cádiz.

El 20 de julio se constituyó una Comisión Gestora Municipal designada por el entonces gobernador civil de Cádiz en funciones, el comandante de Artillería Eduardo Aranda Arquerino (3). Aranda se reservó el cargo de alcalde -que simultanearía con el de gobernador-, nombrando como equipo colaborador al coronel Escolano, al teniente coronel Luis Rodríguez Ponce de León, al comandante Manuel Quevedo, al Secretario Municipal Fernando Domínguez de Cepeda y a los ex-concejales del Ayuntamiento durante la Dictadura de Primo de Rivera Adolfo Núñez Palomino, Juan Luis Martínez del Cerro y Francisco Sánchez Cossío (4).

Tres días más tarde, el general Queipo de Llano se dirigió por radio al pueblo de Cádiz para pedir la normalización de los servicios públicos, la reincorporación a los puestos de trabajo y la apertura de comercios y establecimientos (5).

Ramón de Carranza, último alcalde de Cádiz durante la Dictadura, llegó a la ciudad procedente de Sevilla el 26 de julio, en una avioneta que aterrizó en la Playa de la Victoria. Allí sería recibido por un nutrido grupo de adeptos a la sublevación contra la República encabezados por su yerno Eduardo Aranda, en ese momento, como se ha señalado, alcalde y gobernador civil de Cádiz en funciones. Ese mismo día, Carranza, para demostrar su abierta adhesión al golpe militar, abrió una suscripción en el domicilio de Acción Ciudadana para recabar fondos para las tropas nacionales. La Banca Aramburu, el Banco de España, la Unión Patronal Gaditana y el Banco Hispanoamericano se sumaron a esta iniciativa. La lista de suscriptores fue encabezada por antiguos colaboradores de Carranza y miembros de destacas familias de la burguesía gaditana: Daniel MacPherson, los Marqueses de la Vega de Sagra, José Luis Lacave, Luis Bensusan Martínez, Luis Álvarez Ossorio y Bensusan, Manuel Blázquez y Paul, José de Bedoya, Antonio Blázquez y Martínez de Pinillos, Angel Picardo y Juan J. Martínez del Cerro (6).

El gesto tuvo sus resultados porque, como se había previsto, el 29 de julio Aranda delegaría en su suegro los cargos que ostentaba, conservándose el equipo municipal formado una semana antes (7). Las antiguas redes caciquiles de la provincia de Cádiz de los últimos años de la Restauración entraron nuevamente en funcionamiento.

Carranza, en su discurso de entrada, emplearía el tono imperante en este momento en las filas nacionales: comenzaba diciendo que su objetivo era salvar España de los enemigos de la Patria utilizando los mismos procedimientos por ellos empleados, salvo, según afirmaba, sus gestos crueles e inhumanos. A su juicio, los marxistas asesinaban a aquellos que no compartían sus ideas en presencia de sus seres queridos y disfrutando de la tortura. Además, éstos no 
amaban a España ya que su grito era ¡viva Rusia! y ¡viva Lenin!. Por ello, bajo su punto de vista, convenía luchar contra ellos ya que, de otra forma, se llegaría al fin de la raza española. Por último, señaló que emplearía lo poco que le quedaba de vida a conseguir este objetivo (8).

En estado de guerra, la labor política de Carranza iba a estar limitada y condicionada por el discurrir de los acontecimientos, sin que la elaboración de un plan de trabajo pudiese garantizar unas directrices aplicables con seguridad. Por ello, aunque su intención fue la de reanudar su programa de gobierno municipal interrumpido tras la proclamación de la República, objetivo al que aspiró desde entonces, sólo pudo tomar diversas decisiones coyunturales. En este sentido, dictaminó la restitución de los nombres de las calles cambiados después del 14 de abril de 1931, la municipalización de los artículos de primera necesidad en previsión de problemas de abastecimiento o el establecimiento de comedores asistenciales (9).

\section{Los efectos de la guerra en la ciudad}

Debido a que Cádiz fue controlado con rapidez por las tropas nacionales, los efectos directos de la guerra en la población fueron mínimos. En la mañana del 6 de agosto la ciudad fue bombardeada por barcos republicanos en la zona de la Alameda de Apodaca sin más consecuencias que algunos destrozos materiales. Pocos días más tarde dos aviones hicieron fuego, produciendo cinco bajas y daños en edificios de mayor importancia (10).

Hasta este momento no se habían dictado en la ciudad normativas para la población civil en caso de bombardeo. Pero, en vista de las circunstancias, el 27 de agosto se publicó la siguiente disposición: ante el peligro de ataque, la señal de alarma serían cuatro cañonazos de la Batería de balanzat del Parque Genovés. A ser posible, las sirenas de las fábricas y las campanas de los templos deberían también ayudar en la alarma. Tras el aviso, los vecinos tendrían que seguir las siguientes instrucciones: las personas que en esos momentos estuviesen en la calle se refugiarían en el edificio más próximo, aquellos que se encontrasen en pisos altos tendrían que trasladarse a las plantas bajas o sótanos en habitaciones que no tuviesen comunicación con patio o patinillo y colocándose siempre arrimados a los muros $\mathrm{y}$, por último, mientras durase la alarma quedaba completamente prohibida la circulación por plazas y calles, tanto de vehículos como de personas, salvo, naturalmente, aquellos que estuviesen destinados a la defensa de la ciudad (11).

El 6 de agosto Queipo de Llano enviaría un telegrama en el que, con el fin de reestablecer la normalidad, se designaba al teniente coronel de Caballería Eduardo Varela Valverde como gobernador civil, quedando Carranza sólo al frente del Ayuntamiento (12). La decisión no fue aceptada de buen grado por éste ya que, tras manifestar no haberse fatigado lo más mínimo al frente de los dos cargos, puso, despechado, a disposición de la autoridad el puesto de alcalde. Sin embargo, su renuncia no fue aceptada por las autoridades nacionales. El 
general Varela le rogó que por patriotismo no abandonara la Alcaldía en tan delicado momento, y Queipo de Llano, en el transcurso de una visita a Cádiz el 9 de agosto, se negó a aceptar la dimisión que Carranza le presentó después del acto celebrado en la Plaza de San Antonio, señalando que aquello sería considerado como una deserción (13).

Durante los primeros días de la guerra se organizaron en Cádiz diversos actos de carácter patriótico. El domingo 2 de agosto tuvo lugar en la Plaza de Mina una manifestación en la que participaron todas las autoridades militares y en la que la Banda Municipal interpretó diversos himnos y marchas (14). El 15 de agosto siguiente se celebró un acto de restitución de la bandera bicolor en todos los edificios oficiales (15). La «auténtica bandera nacional», como se indicaba en la prensa, fue izada en el Palacio Municipal, en los Gobiernos Civil y Militar, en el Casino Gaditano (sede de Falange Española en este momento) y en otros edificios oficiales (16).

Asimismo, la despedida el 22 de agosto de las fuerzas expedicionarias ciudadanas fue otro motivo para organizar un acto de exaltación patriótica (17). De igual modo sucedería en el acto de desagravio al Sagrado Corazón de Jesús que fue organizado en la Catedral el 30 de agosto tras el asalto al Cerro de Los Angeles en Madrid (18).

La celebración de actos de este carácter fue constante en este período para contrarrestar el desánimo de la guerra, hasta el punto de que, tras el bombardeo de los dos aviones republicanos en el que murieron tres hombres, una mujer y dos niños, tropas falangistas entonando himnos recorrieron las calles de Cádiz entre vítores, prolongándose la manifestación hasta el atardecer, momento en el que fue arriada la bandera. El entierro de las víctimas tres días más tarde propició la organización de otro acto patriótico (19).

Mientras, desde la Alcaldía se intentaba llevar a cabo una gestión política al dictado de los acontecimientos. Así, a las primeras medidas ya comentadas se unieron las del nombramiento de los generales Queipo de Llano, Varela y López Pinto como hijos adoptivos de Cádiz (20). También se reanudó el culto en la Capilla del Cementerio, se restituyeron los crucifijos y cuadros de la Virgen del Rosario en las aulas de las escuelas (21), el lienzo de la Virgen de la Palma en el retablo callejero de la calle del mismo nombre y la estatua del obispo Silos Moreno en la plaza de la Catedral (22).

Otras medidas seguían directrices de carácter general en la zona nacional como la celebración semanal -desde noviembre de 1936- del «Día del plato único» que consistía en donar el dinero ahorrado en comida ese día para obras benéficas (23), el cambio de nombre de calles por otros que hacían referencia a personajes relacionados con la nueva situación política (24) y la organización de una comisión depuradora para la destitución de los funcionarios municipales que hubiesen pertenecido a alguno de los partidos encuadrados en el Frente Popular, para el despido de los funcionarios interinos nombrados por las 
Corporaciones republicanas y para la contratación del personal que llenase los puestos dejados libres por los ceses. Esta comisión, que llegó a expulsar a ciento cinco trabajadores, estuvo formada por Rodríguez y Ponce de León, Núñez Palomino y Martínez del Cerro (25).

Simultáneamente, la prensa oficial informaba sobre denuncias, detenciones e interrogatorios en el Cuartel General de Falange Española (en el Casino Gaditano). Asimismo, la Comandancia Militar difundió una nota en la que se manifestaba que serían fusilados en el acto todos los vecinos varones de las fincas donde se ocultasen individuos perseguidos (26). El objetivo buscado era el de reducir los «focos aislados de rebeldía» existentes en las azoteas de casas de los Barrios de Santa María y de La Viña (27).

\section{El papel de Cádiz en la contienda: buscando protagonismo en el bando nacional}

Por estas fechas tiene lugar la primera toma de contacto de Ramón de Carranza con el general Franco. Como hizo pocos días después del golpe militar del 18 de julio, volvió a pedir cargos de relevancia. En esta ocasión solicitaba ser nombrado Almirante de la Flota Nacional como un favor especial, según decía, para que pudiese coronar su vida sirviendo a la Patria.

Recordando oportunamente su carrera militar y su Cruz Laureada, se dirigió por carta a Francisco Franco el 12 de septiembre de 1936 desde Sevilla, en donde se encontraba visitando a Queipo de Llano para pedirle que lo pusiera al frente del Batallón de Cívicos de Cádiz en su marcha hacia Madrid (28). Tanto la solicitud hecha a Queipo de Llano como la dirigida a Franco fueron denegadas. Su avanzada edad y el delicado estado de salud en el que se encontraba fueron los argumentos utilizados para no aceptar sus pretensiones. No obstante, Franco, en carta fechada en Cáceres el 15 de septiembre, le agradeció su interés y patriotismo y le explicó que aquel mando ya estaba concedido al almirante Francisco Moreno Fernández, del que tenía muy buenas referencias (29).

A pesar de ello, Carranza, inasequible al desaliento, envió otra misiva el 20 de septiembre en la que, expresando su desilusión, aconsejaba a Franco sobre el futuro curso de la guerra que él pensaba se desarrollaría en el mar (30). Terminaba manifestando que su larga experiencia y patriotismo eran puestos nuevamente a disposición del General en caso de que lo requiriese.

Las medidas tomadas por Carranza para la formación del mencionado Batallón de Milicianos que el mismo pretendía conducir hacia Madrid en agosto de 1936, darían un cierto protagonismo a la ciudad dentro del bando nacional. El alcalde, pensando que la población de Cádiz en general mostraba cierta apatía en participar activamente en la guerra, a excepción de los miembros de la Falange Española, decidió que era necesario organizar una guardia cívica que auxiliase a las tropas. Los servicios serían prestados dentro de la población y, 
voluntariamente, se podrían trasladar al frente. Por decisión de Queipo de Llano y en contra de la opinión de Carranza, el Batallón de Milicianos sería dirigido por el comandante Enrique Muñoz, estableciéndose su cuartel en el local del Centro Mercantil e Industrial en la calle Ancha. El objetivo último de esta organización era el de ofrecer la posibilidad de adherirse al Movimiento Nacional sin necesidad de pertenecer a la Falange Española (31).

Mientras esto sucedía, continuaron celebrándose actos de carácter patriótico en la ciudad. Con motivo del XIII aniversario del golpe militar de Miguel Primo de Rivera se organizó un homenaje al general jerezano en el que se buscaban paralelismos entre la acción regeneradora de la Patria de Primo de Rivera y la del Movimiento Nacional. En aquel acto se dijo que los éxitos del Marqués de Estella provocarían la envidia de sus enemigos y el inicio de una campaña en su contra que terminaría por desmoronar la fundada esperanza del total resurgimiento español, arrastrando en su caida a la Monarquía incapaz de resistir por sí sola los ataques de los malos patriotas. Pero ellos, según se indicaba, no supieron adivinar el peligro que para el país se acercaba: la revolución marxista, a la que se calificaba de azote del mundo civilizado. No obstante, un nuevo grupo de hombres, se terminaba diciendo, se levantaría de nuevo para salvar a España del comunismo y la masonería (32).

Asimismo, diversos hechos se aprovecharían para la organización de nuevos actos de exaltación patriótica en la ciudad, tales como el regreso a Cádiz de uno de los defensores del Alcázar de Toledo, el Teniente de Artillería Tomás Ravina (33), la constitución de la Asociación de Mujeres Tradicionalista ( «Las Margaritas») (34), la colocación de la primera piedra del monumento en honor del Ejército (35), la reposición de las imágenes de los Santos Patronos -San Servando y San Germán- sobre sus columnas de mármol en el muelle de la ciudad (36), la celebración de la toma de Bilbao por las tropas nacionales en junio de 1937 (en la que participó la Compañía de Milicianos de Cádiz) (37), el acto de eliminación de la lápida de la fachada de la casa natal de Mendizábal en la calle San Francisco (38), los festejos de la primera Fiesta Nacional el 18 de julio de 1937, con desfiles de tropas, Te Deum en la Catedral y conciertos callejeros de bandas militares (39), y las ocho representaciones de la zarzuela «Cádiz» de Federico Chueca en el Gran Teatro Falla, a la que asistieron representaciones de la Falange, Requetés y las Milicias, ya que esta obra -se dijo en su momento- trataba «sobre el Cádiz que no pudo invadir Francia, lo mismo que ahora no lo ha podido invadir Rusia» (40).

Entre estas manifestaciones patrióticas destacó la que tuvo lugar con motivo de la visita que a la ciudad realizó el general Queipo de Llano. Ramón de Carranza dispuso un programa de actos que recordaba a aquellos desarrollados durante las estancias en la capital de Alfonso XIII y Miguel Primo de Rivera en la Dictadura. Con el ánimo de mostrar al Jefe de los Ejércitos de Sur su adhesión, el alcalde se propuso a preparar a la ciudad para este acontecimiento que se celebraría en marzo de 1937, con motivo del descubrimiento de una lápida en honor del «Mártir de la Patria» José Calvo Sotelo y de la entrega de la Bandera 
Nacional al Regimiento de Infantería de Cádiz (amadrinada por la esposa de Pemán). La Alcaldía publicó un bando por el que se obligaba a sanear y engalanar las fachadas de las Plazas de San Juan de Dios, San Francisco y Loreto (que a partir de esas fechas se denominaría de Calvo Sotelo) y del paseu de Canalejas (41): Los discursos de exaltado contenido patriótico, tanto de Carranza como de Queipo de Llano, hicieron referencia una vez más a las virtudes morales de Calvo Sotelo y la actuación del ejército nacional para, decían, liberar a España del marxismo (42).

\section{Cádiz, ciudad de retaguardia}

Tras pasar Málaga el 7 de febrero de 1937 bajo el control de las tropas nacionales, los únicos episodios bélicos producidos en Andalucía fueron el asedio republicano al Santuario de la Virgen de la Cabeza (Andújar) y un bombardeo alemán sobre Almería. Esto propició que Cádiz pasara a cumplir claramente funciones propias de la retaguardia, encargándose de prestar servicios médicos a soldados heridos en el frente y del abastecimiento de ropas y víveres.

En estos meses, Carranza nuevamente se puso en contacto con el general Franco, visitándolo esta vez personalmente en Salamanca y Burgos. El pretexto fue gestionar diversos asuntos considerados necesarios para Cádiz. Estas entrevistas tuvieron lugar en diciembre de 1936 y en abril y mayo de 1937 y mostraban la misma intención que aquellas tenidas con Miguel Primo de Rivera durante la Dictadura (43). A la vuelta de las mismas, se mostró entusiasmado con los resultados obtenidos, aprovechando la oportunidad para mostrar su apoyo a Franco (44).

Pero tanta actividad terminó por agravar su precario estado de salud a partir de junio de 1937. El 9 de julio dedidió, muy a su pesar, presentar su dimisión como alcalde ante el general Queipo de Llano. En la Sesión Plenaria del 16 de julio siguiente fue aceptada esta renuncia y nombrado alcalde interino Pedro Ogalla Torres (45). El 2 de agosto se hizo cargo del puesto Juan de Dios Molina Arroquia, el cual expresó su intención de continuar con la labor emprendida por su predecesor (46).

Las palabras de despedida de Juan Luis Martínez del Cerro, en nombre de la Corporación Municipal, durante el Pleno en que fue presentada la dimisión revelaban el fuerte respaldo con el que Carranza contaba entonces. Según sus palabras, no se trataba de una dimisión más, a la que protocolariamente bastaba con agregarle un simple voto de gracias y unas líneas en las actas municipales; era la renuncia, continuaba diciendo, de un hombre que se entregó por entero a su labor, sacrificando sus intereses y su resentida salud. A continuación detallaba su actuación política al frente de la Alcaldía, explicativa del por qué a su juicio- se le llamó el «Alcalde Grande». Por último, creyendo expresar el sentir del pueblo de Cádiz, propuso conceder a Carranza el título de Alcalde 
Honorario como premio a sus esfuerzos, solicitud que fue aprobada por unanimidad (47).

El 13 de septiembre de 1937, Ramón de Carranza fallecía en su domicilio de la calle Ancha a los setenta y cuatro años de edad (48), decretándose luto oficial durante tres días.

La posición de Cádiz en la guerra se mantuvo en términos parecidos durante 1938. La actuación política de Juan de Dios Molina continuó con la apertura de expedientes a funcionarios de la República y las detenciones, aunque éstas fueron menos numerosas que durante los primeros meses de la contienda. Asimismo, la Compañía de Milicianos siguió prestando servicio en el frente de batalla, ya cada vez más alejado de Andalucía.

Por otra parte, las instituciones gaditanas dieron nuevas muestras de apoyo a los nacionales con gestos como la instalación de la primera Cruz de los Caídos frente al Gobierno Militar o la celebración de actos festejando la pérdida de posiciones del bando republicano.

A estas alturas de la guerra, Cádiz se había convertido definitivamente en una ciudad de retaguardia que debía ofrecer servicios hospitalarios y de suministro de víveres, ropas y municiones a las tropas del frente de batalla. No obstante, se intentó normalizar la actividad laboral y se celebraron las procesiones de Semana Santa y Corpus Christi, un pequeño ciclo de conciertos del Gran Teatro Falla, corridas de toros en las fechas tradicionales y la temporada habitual de baños del Hotel de la Playa (49).

El 7 de septiembre de 1938 tomó posesión un nuevo gobernador civil, Daniel Arraiza Goñi, encargado de facilitar la concentración en Cádiz, desde el 12 de octubre de 1938, de los 10.000 legionarios italianos que debían ser repatriados (50). Su embarque para Nápoles el día 15 fue aprovechado para organizar un acto de exaltación patriótica presidido por los generales Queipo de Llano y Millán Astray en el muelle de la ciudad. Coincidiendo con ello, llegaron noticias de que el bando nacional exigía una rendición sin condiciones al republicano, tras perder éste ya casi todas sus posiciones importantes (51).

La entrada de tropas nacionales en Tarragona, Reus y Barcelona en enero de 1939 y la toma de Madrid el mes de marzo siguiente permitió que la guerra pudiera darse por finalizada y que, por aquellos que estaban en disposición de hacerlo, el acontecimiento se celebrara jubilosamente en las calles de Cádiz. La zona republicana en Andalucía (Almería, Jaén y parte de las provincias de Córdoba y Granada) fue tomada coincidiendo con la rendición de Madrid (52).

En estas circustancias, el general Varela afirmó que Cádiz había sido uno de los pueblos más influidos por el marxismo. A su juicio, una prueba de ello era que el 18 de julio de 1936 sólo había podido contar con trescientos soldados (entre artilleros e infantes) y con veintidós paisanos (sumando falangistas y 
requetés). Por ello, en su opinión, si Cádiz hubiese sido controlado por los republicanos, el bando nacional no hubiera podido ganar la guerra (53). Con esta declaración Varela revalorizaba su propio gesto pero, indirectamente, revelaba además que quizás la aparente debilidad de los defensores de la República fue menor de lo que el curso de los acontecimientos parecía demostrar.

Finalizado el conflicto, el Ayuntamiento continuó la revisión de expedientes de depuración de funcionarios y se repitieron -ahora con mayor énfasis, si cabe- los gestos de adhesión al Nuevo Estado, que en estos momentos estaba iniciando el proceso de eliminación de cuanto había significado la República (54).

El 28 de mayo de 1939 llegó a la ciudad una segunda expedición de 12.000 legionarios italianos para ser repatriados. Ésta fue despedida en el muelle por Queipo de Llano y Serrano Suñer (55). Dos semanas después 1.500 aviadores embarcaron hacia Nápoles (56) y una tercera expedición de legionarios -5.000 más- salió del puerto de Cádiz (57). La ocasión fue empleada una vez más para celebrar actos de carácter patriótico bajo la presidencia de los generales Queipo de Llano y Kindelán.

Mientras llegaban noticias de la declaración de guerra de Gran Bretaña, Francia y Polonia a Alemania, en la ciudad comenzó a entrar en funcionamiento el régimen de racionamiento, justo cuando la escasez de alimentos empezó a ser evidente. Se cerraba así un período especialmente difícil y se abría otro que resultaría ser no menos arduo.

\section{NOTAS.}

(1) Vid. PAYNE, S.G., La revolución y la guerra civil española, Barcelona, 1972; PRESTON, P. (ed.), Revolución y guerra en España 1931-1939, Madrid, 1984; VILAR, P., La guerra civil española, Barcelona, 1988 ( $3^{\mathrm{a}} \mathrm{ed}$.).

(2) Cfr. Diario de Cádiz, domingo 19 de julio de 1936 (edición de la tarde).

(3) Cfr. Diario de Cádiz, martes 28 de agosto de 1936 (edición de la mañana).

(4) Cfr. Actas Capitulares, Acta n ${ }^{\circ}$ 1, 20 de julio de 1936, tomo 66 (17-IV-1936 a 5-VIII-1936). Punto único.

(5) Cfr. La Información, jueves 23 de julio de 1936.

(6) Cfr. La Información, domingo 26 de julio de 1936 y martes 28 de julio de 1936.

(7) Simultáneamente a esto, el primogénito de Carranza, el Marqués de Sotohermoso, presidiría la Alcaldía de Sevilla. Cfr. Diario de Cádiz, jueves 23 
de agosto de 1936 (edición de la tarde); Diario de Cádiz, miércoles 15 de septiembre de 1937 (edición de la mañana).

(8) Cfr. La Información, jueves 30 de julio de 1936; Diario de Cádiz, jueves 30 de julio de 1936 (edición de la mañana). (Una foto de gran tamaño de Carranza acompañaba este discurso en la primera página del Diario de Cádiz).

(9) Cfr. Actas Capitulares, Acta n 3, 5 de agosto de 1936. Tomo 66 (17-IV-1936 a 5-VIII-1936). Punto 6. Actas Capitulares. Acta $\mathrm{n}^{\circ} 4,12$ de agosto de 1936. Tomo 67 (5-VIII-1936 a 5-II-1937). Punto 10. Actas Capitulares. Acta ${ }^{\circ} 5$. Tomo 67 (5-VIII-1936 a 5-II-1937). Punto 10.

(10) El bombardeo tuvo lugar a las doce y media de la mañana del 25 de agosto. las primeras bombas cayeron en el domicilio de Guillermo Supervielle en la calle Fermín Salvochea. En la Alameda de Apodaca, frente a la calle de Isabel la Católica, en la casa de los MacPherson, y en la Casa Cuartel de la Guardia Civil se arrojaron las demás. Entre los fallecidos se encontraban José María Bensusan y Silóniz. Luis Álvarez Ossorio y Bensusan, colaborador de Carranza en la Alcaldía en estos momentos, resultó gravemente herido. Cfr. La Información, miércoles 28 de agosto de 1936.

(11) Cfr. La Información, jueves 27 de agosto de 1936.

(12) Cfr. Diario de Cádiz, viernes 7 de agosto de 1936 (edición de la tarde).

(13) Cfr. La Información, martes 11 de agosto de 1936.

(14) Cfr. La Información, martes 4 de agosto de 1936.

(15) Cfr. La Información, viernes 14 de agosto de 1936; Diario de Cádiz, viernes 14 de agosto de 1936 (edición de la mañana); Diario de Cádiz, domingo 16 de agosto de 1936 (edición de la mañana).

(16) Cfr. Diario de Cádiz, domingo 16 de agosto de 1936 (edición de la mañana); Diario de Cádiz, sábado 18 de agosto de 1936 (edición de la mañana).

(17) Cfr. La Información, domingo 23 de agosto de 1936 (edición de la mañana).

(18) Cfr. La Información, lunes 31 de agosto de 1936.

(19) Cfr. La Información, viernes 28 de agosto de 1936.

(20) Cfr. Actas Capitulares, Acta n8, 11 de septiembre de 1936. Tomo 67 (5VIII-1936 a 5-II-1937). Punto 26.

(21) Con respecto a la restitución de los crucifijos y cuadros de la Virgen del Rosario en las escuelas, Carranza declararía que «las escuelas tienen la misión de 
formar el alma y los corazones de los niños, enseñarles la Religión y patriotismo, crear cristianos y ciudadanos. La base de la ciudadanía es la Religión y el amor a la patria. Este debe ser el pensamiento que inspire la actuación del municipio gaditano. Hay que crear ciudadanos útiles, sanos y fuertes, cumplidores de sus deberes religiosos y para con la Patria. Hay que producir los hombres del porvenir (...) todos hemos de convivir juntos en esta empresa: ricos y pobres, poderosos y humildes»; La Información, miércoles 2 de septiembre de 1936.

(22) Cfr. Diario de Cádiz, jueves 10 de septiembre de 1936 (edición de la tarde).

(23) Cfr. Diario de Cádiz, domingo 15 de noviembre de 1936 (edición de la mañana); La Información, martes 9 de febrero de 1937.

(24) Los cambios de rótulos fueron los siguientes: la Plaza del Palillero pasaba a llamarse del General Varela; el Campo de Balas, Avda. del General Sanjurjo; la calle José Ramón de Santa Cruz, José María Pemán; la calle de San Francisco, Generalísimo Franco; y la calle Sagasta, Queipo de Llano; Cfr. Actas Capitulares, Acta ${ }^{\circ}$ 9, 26 de febrero de 1937, tomo 68 (5-II-1937 a 11-VIII1937). Punto 15.

(25) Cfr. Actas Capitulares, Acta n ${ }^{\circ}$ 4, 12 de agosto de 1936, tomo 67 (5-VII1936 a 5-II-1937), punto 12; Actas Capitulares, Acta n 7, 2 de septiembre de 1936, tomo 67 (5-VIII-1936 a 5-II-1937), punto 15; Actas Capitulares, Acta ${ }^{\circ}$ 8, 11 de septiembre de 1936, tomo 67 (5-VIII-1936 a 5-II-1937), punto 6; Actas Capitulares, acta $\mathrm{n}^{\circ}$ 9, 18 de septiembre de 1936, tomo 67 (5-VIII-1936 a 5-II1937), punto 10.

(26) Cfr. Diario de Cádiz, domingo 30 de agosto de 1936 (edición de la mañana).

(27) Cfr. Diario de Cádiz, martes 11 de agosto de 1936 (edición de la mañana), Diario de Cádiz, domingo 6 de septiembre de 1936 (edición de la mañana), vid. REIG TAPIA, A., Ideología e historia: sobre la represión franquista y la guerra civil, Madrid, 1984.

(28) Cfr. FUNDACION NACIONAL FRANCISCO FRANCO: Documentos inéditos para la Historia del Generalísimo Franco, Madrid, 1992, pp. 81-84.

(29) Cfr. Ibidem, pp. 84-85.

(30) Vid. ALPERT, M., La guerra civil española en el mar, Madrid, 1984.

(31) Cfr. Diario de Cádiz, lunes 31 de julio de 1936 (edición de la mañana).

(32) Cfr. La Información, domingo 13 de septiembre de 1936.

(33) Cfr. La Información, jueves 1 de octubre de 1936. 
(34) El llamamiento fue hecho con estas palabras: « Gaditanas; Hacen falta mujeres patriotas como aquella Lola la Piconera que inmortalizó nuestro gran José María pemán, que en una exaltación de sus patrióticas virtudes llegó hasta la muerte, engañada por un malvado masón pero creída en que luchaba por la independencia de su España y por todas las grandezas pasadas. Aquella Lola la Piconera que cantaba la libertad de su Patria diciendo que era la mayor y la primera de sus angustias, para terminar diciendo que si no fuera libre España ella no podría cantar. ¡Mujeres de Cádizj Aún no es libre del todo España de esa lacra marxista. Aún queda tierra que pisan las plantas traidoras de los enemigos de España y que la tienen convertida en sucursal de la soviética Rusia (...) Ninguna mujer española puede permanecer insensible ante este llamamiento, y seguros estamos de que por su parte la mujer gaditana sabrá responder una vez más, como ninguna, a este requerimiento»; La Información, domingo 4 de octubre de 1936.

(35) Cfr. Actas Capitulares, Acta n ${ }^{\circ} 23,11$ de diciembre de 1936, tomo 66 (5VII-1936 a 5-II-1937), punto 16.

(36) Cfr. La Información, jueves 22 de octubre de 1936.

(37) Cfr. Diario de Cádiz, martes 22 de junio de 1936 (edición de la mañana).

(38) El razonamiento dado por Juan J. Viniegra, promotor de esta iniciativa en el Ayuntamiento, fue el siguiente: «Pedí que esa lápida desapareciera, porque ¿no se ha convenido que hay que extirpar de España la masonería? Pues sencillo es ir borrando de plazas y calles nombres de masones que mientras se dejen, contribuimos nosotros mismos, los de esta bendita España nueva que ahora nace, a que sigan inmortalizándose y a que los extranjeros que nos visiten y sepan algo de nuestras cosas se hagan cauces al ver que no siempre concuerdan nuestras predicaciones con nuestros hechos; $y$, repito, como eso es porque han tenido la fortuna de conseguir siga siendo secreta esa secta para ocultar sus nombres o para no dejar prueba documental de ellos, creo que mi petición es bien recibida». Un pliego para estampar firmas en apoyo de esta decisión fue expuesto en el Ayuntamiento, como ya era habitual, durante varios días. Diario de Cádiz, domingo 27 de junio de 1937 (edición de la mañana), Cfr. Diario de Cádiz, martes 6 de julio de 1937 (edición de la mañana).

(39) Cfr. Diario de Cádiz, lunes 19 de julio de 1937 (edición de la tarde).

(40) Diario de Cádiz, miércoles 21 de octubre de 1936 (edición de la tarde).

(41) Cfr. Diario de Cádiz, jueves 25 de febrero de 1937 (edición de la mañana), cfr. La Información, jueves 25 de febrero de 1937; Diario de Cádiz, lunes 1 de marzo de 1937 (edición de la tarde); La Información, lunes 1 de marzo de 1937. 
(42) En palabras de Carranza, «iqué diferente habría llegado a ser nuestra nación regida por Calvo Sotelo y gobernada por el sistema corporativo que habría implantado; Hombres como él rara vez se producen y por ese motivo es más de lamentar el vil asesinato que nos privó de su preciada vida», La Información, lunes 1 de marzo de 1937.

(43) Cfr. Diario de Cádiz, viernes 1 de enero de 1937 (edición de la tarde); La Información, sábado 2 de enero de 1937; Diario de Cádiz, sábado 3 de abril de 1937 (edición de la mañana); La Información, martes 25 de mayo de 1937.

(44) Cfr. Diario de Cádiz, viernes 29 de enero de 1937 (edición de la mañana).

(45) Cfr. Actas Capitulares, acta n 30 , Sesión Extraordinaria, 16 de julio de 1937, tomo 68 (5-II-1937 a 11-VIII-1937), punto 2.

(46) Juan de Dios Molina Arroquia fue durante la Alcaldía de Carranza en la Dictadura de Primo de Rivera responsable de la Comisión Gestora de los Servicios Municipalizados de Agua y Luz. Cfr. La Información, martes 23 de agosto de 1937.

(47) Actas Capitulares, acta n ${ }^{\circ}$ 30, Sesión Extraordinaria, 16 de julio de 1937, tomo 68 (5-II-1937 a 11-VIII-1937), punto 2.

(48) Cfr. Diario de Cádiz, martes 14 de septiembre de 1937 (edición de la mañana).

(49) Vid. ABELLA, R., La vida cotidiana durante la guerra civil. La España Nacional, Barcelona, 1973; GUILLOTO GONZALEZ, F., Cinco años de la historia de Cádiz, 1936-1940, Cádiz, 1988.

(50) Vid. COVERDALE, J.F., La intervención fascista en la guerra civil española, Madrid, 1979; SWARTZ, F., La internacionalización de la guerra civil española, Barcelona, 1971.

(51) Cfr. Diario de Cádiz, 12 al 15 de octubre de 1938 (ediciones de mañana y tarde).

(52) Vid. MARTINEZ BANDE, J.M., El final de la guerra civil, Madrid, 1985.

(53) Cfr. Diario de Cádiz, 18 de julio de 1939 (edición de la mañana).

(54) Vid. RAMIREZ, M., Las fuentes ideológicas de un Régimen (España, 1939-1945), Zaragoza, 1978.

(55) Cfr. Diario de Cádiz, 31 de mayo de 1939 (ediciones de mañana y tarde).

(56) Cfr. Diario de Cádiz, 11 de junio de 1939 (edición de la mañana). 
(57) Cfr. Diario de Cádiz, 24 y 25 de junio de 1939 (ediciones de mañana y tarde). 